\title{
To Be or Not to Be? Dilemmas and their Resolution in Literary Translation of Shanta Kumar's Lajjo
}

\author{
SUMAN SHARMA
}

This paper discusses the various dilemmas faced by the translator while translating Shanta Kumar's Hindi novel Lajjo. Taking instances from the translation, the research had involved a comparative analysis of transactions that had taken place between the languages involved. An attempt is made to explain the problematic aspects of this translation and their solutions. Since Hindi and English operate differently at linguistic, expressive, cognitive, geographical and socio-cultural levels, it requires a great deal of diligence and understanding to resolve the dilemmas of translation. This research is possibly the first ever attempt to problematise the translation process involving a Kangri-Hindi text and hence it is believed that the mini theories, so generated will add to the overall understanding of translation phenomena.

Keywords: dilemma, language, choice, equivalence, meaning.

During his/ her life, a human being is often at crossroads and struggles to make choices. The well-known poem, "The Road Not Taken" by famous American poet, Robert Frost takes this dilemma of choice, to a deep philosophical level. The opening lines of the poem are worth producing here;

Two roads diverged in a yellow wood,

And sorry I could not travel both

And be one traveler, long I stood

And looked down one as far as I could

In this poem, the poet narrates an incident, when he was walking through a road in the woods and at a particular point, the road had divulged into two. He was in a dilemma about which road to take; the one which was often used, or the one that was seldom used. Fortunately for the poet, the dilemma was resolved and he took the road, "one less travelled by." For the poet, it was about 'two roads', but for the translator, it is myriad number of roads, which diverge from the time, he decides to translate. This dilemma of choice, for a translator can be compared with the dilemma faced by Hamlet, that was, "to be or not to be." Like Hamlet, the translator is also not sure about the steps he has to take to recreate a faithful rendering.

The very first dilemma that a translator face (especially if he is in research) is about what text to translate. Whether he should take up a foreign language author or the writer from his own country. If he decides to take the 
text from his own country, then there is a dilemma of choice between once own state/ region/ country and other state/ regions. The second problem occurs, when he has to decide, whether he should translate into his mother tongue or out of it (especially in the language of 'metropolitan'). The third dilemma is about the choice of intended audiences; whether he should address his translation to the foreign audiences or to the native audience. If he decides to address the translation to the foreign audiences, then there is the dilemma about whether to direct the translation to the readers of the west or to the readers of third world countries. The fourth dilemma is about what should be the "Skopos" or the purpose of the translation; whether it should be to propagate the source culture to the wider audiences or it should be to domesticate the target language. Finally, during the actual translation, the multitude of choices in the translation of the source text opens up the Pandora's box for the translator, as he struggles to translate the: reduplications, onomatopoeic, compound words, idioms, proverbs, collocations, inflections, expressive, compound verbs and honorifics. The translator is often at a loss about, whether he should go for "word for word" or "sense for sense" translation, remain absolutely fidel to the text or take liberties with it, let his creativity interfere or be a faithful reporter of the text, be loyal to the source text or to the translation.

Linguist Greenberg classified different languages of the world in three groups. English was put in group two, while Hindi was put in group three. According to him, it is often difficult to translate a lexical concept, between the languages in the diverse group (Shanker 2012: 73). Linguistically, there are different grammatical rules for Hindi and English. While Hindi follows 'Subject+Object+Verb' arrangement, English follows, 'Subject+ Verb + Object' syntactic arrangement. In addition, the gender discrimination in Hindi is identified by the verbs, while it is the pronouns that determine the gender distinctions in English (Dwivedi 2012: 59). Hindi and English not only have different number of letters, but also have different number of vowels and consonant. Hindi has fifty-two alphabets out of which eleven are vowels, English have twenty-six alphabets, with only five vowels. This is unlike Sanskrit that is quite "flexible" in the syntactic patterning. Reputed translation studies scholar Mona Baker observes that, "... there are different devices in different languages for creating a texture' and that the text hangs together by virtue of the semantic and structural relationships that hold between its elements" (Baker 1992: 188). This increases the dilemma for the inter-lingual translator, because of the myriad number of such available devices in two diverse languages in question. So, the translator has to build up certain strategies, where he is not only simply transferring the source language devices, but creating an innovative method that satisfies the grammatical norms of the target language.

Interpretation is an important step in "decoding" the meaning of the source text. There are two kinds of interpretation in literary translation. One is "objective interpretation" and the other is "subjective interpretation" 
(Dharankar 2016: 49). The objective interpretation refers to the linguistic aspects of translation, whereas the subjective interpretation relates to; psychological, socio-cultural, cognitive, political and ideological contexts of the translation. In other words, objective interpretation search for exact equivalents, while the subjective interpretation looks for dynamic expressions. This ambiguity which is inherent in any language, becomes acute in case of translation, as here the translator has to interpret not only the meaning, but the intended meaning in all its totality and recode it in the target language.

At times, a single word in a sentence has to be interpreted differently and translated accordingly. For example, during the translation of this sentence: “हाथ जोड़ कर बोली, “जनाब, मुझे क्षमा करें। मैं गरीब हूँ, एक शहीद की विधवा हूँ, आपकी लड़की की आयु की ही हूँ . . . पैर पड़ती हूँ..." कहते कहते लाजो ने उसके पैर पकड़ लिए।

(Kumar 2011: 49). 'She folded her hands and said, "Janaab, please forgive me. I am poor and the widow of a martyr and of your daughter's age . . . I fall at your feet . . . and Lajjo clutched the legs of Bhagat Ram" (Sharma 68). As can be observed, the word "पैर" had occurred twice in this sentence. At the first instance, the word was interpreted as 'feet' which is the exact equivalent of the source language word. This also fitted the Indian context, as a helpless person who depends upon another powerful person for his well-being, usually restore to this trick of falling at the feet of that other person. He/ She places his head at another person's foot to show complete surrender of his being. This was exactly the situation for Lajjo, as she was about to be raped at gun point by Bhagat Ram and she somehow wanted to escape the ordeal. To interpret the same word, when it occurred for the second time was a little bit tricky, as it is the legs, which the 'helpless person' usually clutch and not the 'feet'. So, to interpret this word was problematic for the translator. However, weighing all options, the word was translated as 'legs', as it fitted the context and this strategy also purged the text of repetitions.

Similarly, to interpret the meaning of word 'क्षमा' was also problematic. In actual sense this word can have different meaning in the source language, which depends upon the context and the temporal position of the word in the sentence. The phrase "मुझे क्षमा करें।" could mean; "forgive me" or it could simply mean "refusal" or, as the case in the text is, "to let someone go, without harm'. According to the textual context, Lajjo had not committed any mistake. Instead, it was she, who was being raped, and to escape the ordeal, she is asking her tormentor to let her go. If we go back in the textual world, the translator could have interpreted that, she might have been actually seeking forgiveness for hitting Bhagat Ram. But again, the translator intuitively felt that first interpretation was possibly the correct interpretation and the word was translated as; 'forgive'. 
In certain cases, in spite of the best efforts, the translator is not able to decipher the exact meaning of the original. In such cases he has to either depend upon the author or on his own intuitions to translate the sentence correctly. In other words, either he has to remain faithful to the source text or let his fecund imagination intervene and try to clear the ambiguity. For example, deciphering the meaning of this sentence was problematic. "कांता दूर टिमटिमाते दीये की तरफ देखती रही।" (Kumar 2011: 55). In this sentence, it is not clear, whether the lamp is outside or inside the house. On first impulse, the translator thought of seeking the help of author in comprehending this sentence, but finally this idea was dropped, ambiguity in the translation was retained. So, the sentence was translated as: "Kanta stared at the fluttering Diya, placed at a distance" (Sharma: 78). This ambiguity of meaning was also exhibited in this sentence: "इसी प्रकार एक चारपाई और लायी गयी और सबको बिठा दिया गया)"। Kumar 2011,. (33 While interpreting the meaning of this sentence, a question had troubled the translator's mind; whether all guests were asked to sit or they were requested to sit or if we let our imagination run wild, it can also be surmised, that they were forcefully made to sit on the charpai. However, being a native of Kangra himself, the translator very well knew that the people of rural Kangra are quite respectful towards their guests. Hence, the translator could visualize the entire scene and the sentence was translated as: "Similarly, another cot was also brought and all were requested to sit on it" (Sharma: 42). Apparently, the translator has translated according to approximation or probability, which is akin to being infidel to the source text.

The fact that the languages reflect various facets of its user, problematise the search for exact equivalence. For example, how will an Indian translator, translate an English sentence, "He is keeping a dog" in Hindi. A good translator will replace the word "keep" with the Hindi word "पालना", because in India people rear a dog and not keep them. At deeper psychological level, keeping something is a sign of dominance, authority and detachment, and rearing someone a is sign of love, sympathy and selfishness. Baker writes in this regard: "Language therefore differ widely in the way they are equipped to handle various aspects of experience, possibly because they differ in degree of importance or relevance they attach to such aspect of experience" (86).

At times a translator has to find the exact equivalent of the "hyponym" used in the source language (Baker 1992: 20). For example, speech has different lexical sets as; murmur, mumble, mutter and whispers. If the word "mutter" is to be translated into Hindi, then it will only have to be translated with its exact hyponym, "बड़बड़ाना" and the word cannot in any case, be translated as, “फुसफुसाना". To translate the Hindi word “चारपाई" was also problematic, as there is not exact equivalent of this word in the target language. The word "charpoy" is accepted in standard English and the word could have been translated as such, but then it seemed that something is missing here. As the word "charpoy", streaked of colonial legacy, the translator thought of retaining the word as such and adding its meaning in the 
glossary. However, subsequently it was discovered that the writer, himself had explained the meaning of this word in the text as, "the cot made up of bamboo and baan" (Sharma: 42). So, the translator had dropped the idea of retaining this word and simply translated the word as "cot." Another problem with finding the equivalents is that a word may have more than one surface meaning. It may have a "prepositional meaning" and "expressive meaning." (Baker 1992: 13). For example, the English equivalent of the Hindi word dupatta is the word "mantle", but the question is, whether the expressive, presupposed and the evoked meanings of the two words match perfectly? May be "not", because to put on the mantle may be fashionable for western women, but to wear it is socio-culturally, imperative for the south Asian women. The sentences like; "नहीं भाभी, ऐसी भी क्या बात है।" is quite common in Hindi, but its literal equivalent is unheard of in the target language (Kumar 2011: 50). So, to translate such sentences is a challenge in itself and the translator had to translate such sentences according to the conventions of the target language. The translator therefore had translated the above quoted sentence as, "Bhabhi, you are not putting it right!" which is perfectly acceptable in the Standard English.

There is no "orthographic" correspondence between the "elements of meaning" and the words in the two distinct languages (Baker 1992: 11). For example, a Hindi, phrase like "अनुदान का धन" having three words, was not translated with its three-word equivalent, but with a single word, "grant", as the word was closest to the original phrase (45). Similarly, a Hindi word, "अभागिन" having no orthographic equivalent in English and hence was translated with the two words as, "unfortunate girl." The phrase, "बन्दूक की गोली" was translated with a single compound word, "gunshot". Some languages like Hindi, allows the body parts like eyes and hands to act as independent subjects having their own will, but English does not have such conventions. For example, this Hindi phrase, "उसके अन्दर की आंखे सीधी घूरने लगी" (Kumar 2011: 47) is quite correct according to source language norms. Similarly, the sentence like: "प्रेम का हाथ ऊपर के फट्टे को पकड़ कर थक चूका था|" makes perfect sense to the source readers, where in the body parts like "eyes" and "hands" can act as independent subjects. However, in English, only the human beings can have the will of their own. So, the first sentence was translated as: "He then lifted his goggles a little and stared her directly", and the second sentence was translated as "Prem was tired of holding the chain" (Sharma: 68). Anyway, the translation like: "His eyes started staring at her" and "Prem hands was tired ..." would have sounded weird, if not altogether incomprehensible to the target audience.

In many instances, the translator has to decipher the message according to the context. In these cases, the insistence on exact surface equivalents may violets the semantic usage of Standard English. Hence, it becomes imperative that such words are translated with much thought and consideration. Hence, the expressions such as, "छोटा भाई" was not translated as "small brother", but 
was translated as, "younger brother". Similarly, the word, "पढ़ता", as in the sentence, "रविन्द्र आठवीं कक्षा में पढ़ता था" (43) was translated as "studying" and not as "reading". Likewise, the Hindi word "दूसरा" in the sentence: “दूसरे कमरे से सुमेर के कराहने की आवाज़ आई।" was translated as "another" (Kumar 2011, 56). Anyhow, it would have been grossly inappropriate to translate the word with its surface equivalent, "second" as it would have betrayed the intention of the author. Many a times the translator is not able to find the word having an exact strength as the word in a source language. For example, the word "savage" is more forceful than the word "ugly". Hence, if the translator has to replace the Hindi word "बदमाश" in English, he has to find an equivalent word with the same force. At times when there is a choice to use, either English version or the indigenous version of the unique proper nouns, the translator often faces a catch twenty-two situation because if the translator chooses the English version, he gets stuck into an ideological debate of "betrayal" and "erasures." On the other hand, indigenous choice may leave the audiences clueless and confused. For example, for quite a while there was intense debate in the mind of the translator, about how to translate the source Hindi word "Bharat." For the westerners, our country is known by India and hence to retain the word "Bharat" in the translation could have caused confusion in such audiences' mind. However, it would have been considered appropriate to retain the word as such in view of ideological discussions regarding bringing audiences to the text.

To translate the reduplicated and onomatopoeic expressions too is problem in inter-lingual translation. In most of cases, there is no equivalent reduplications in the target language, and the original reduplications have to be replaced by the single word, that is closer to its meaning and function. For example, Hindi reduplication 'कहते कहते' was simply replaced as 'said' as to translate it as 'said said' would have been grossly absurd. Similarly, another reduplication, "रात रात" was translated as "instantaneously." The onomatopoeic expressions too were translated with single words. For example, the expression, "घई घर" which was used in the following sentence, “बस आई और घर्र घर्र की आवाज करती हुई गुजर गयी)।Kumar 2011, (72 was replaced by the word "roared" and the sentence was translated as, "The bus roared passed them" (Sharma: 106). Similarly, another onomatopoeic expression, "छक छक" in the Hindi sentence: "गाड़ी छक छक चली जा रही थी" (Kumar: 68) was translated with the word, "swift" and the sentence was translated as: "The train was moving swiftly" (Sharma: 100).

Translation is always coloured and the reason for this "awkwardness" is because of the difference between the, "selectional and collocations" restrictions imposed in the two languages (15). It is due to the collocational restrictions put up by the language that, while the teeth are brushed in the English, they are cleaned in the Hindi. In Hindi we say, "काम कर देना" while in English it is "finish off my business." The translator often faces dilemma in 
transferring the exact meaning, while looking for collocational equivalent in the target language. Baker writes: "Translation often involves a tension-A difficult choice between what is typical and what is accurate" (68). Words in a language have different "collocation range" (62). For example, the word "run" has vast collocation range, while the collocational range of the word "shrug" is limited. Even within a language the "collocation range" of words keep on expanding, due to various reasons, one of which may be the translation process (50). In addition, new and unusual collocational patterning are also accepted within a language. This neo combination of words results in giving a new texture to the language.

Sometimes the collocation patterning in Hindi and English does match. It is exactly for this reason that it is quite easy to translate an English sentence: "The people break the law," as, "लोग कानून तोड़ते हैं". This is because the English word "break" and Hindi word "तोडना" are inter-lingual synonyms. However, even if the "surface patterning" of collocation in two languages appears to match (54), still there is no guarantee that their meaning would "map completely" (Baker 1992: 57). Sometimes translator face difficulty in translating nouns from Hindi into English, because of the different collocational restriction put up in the two languages. For example, in this original sentence: "तू रात रात मैं खद्दर के सफ़ेद कपडे पहन कर नेता बन गया।" (Kumar 2011: 28), was translated as, "You donned khaddar cloths of white colour and became a politician, instantaneously (Sharma: 33). While it is acceptable to say, "खद्दर के सफ़ेद कपडे" in Hindi, it is not acceptable to translate it as, "khaddar cloths of white" because collocational patterning of English, requires that the word "colour" collocates with the word "white" to complete the sense. In one of the sentences of the source text, a character Krishan Dyal asks the SDM of Palampur, "विशवनाथन ,मुझे दो टूक जवाब चाहिए।" (Kumar 2011: 64). Some of the equivalents of the Hindi collocation "दो टूक" are 'blatant' and 'candid', but when you look at the context, such equivalents offer altogether different meaning. Similarly, the collocation "दो तीन" was not translated as "two, three" but, as "a few". So, it can be observed here that only the meaning and not the aesthetics was transferred.

The rules and conventions for cohesion are different in any two languages. Baker defines cohesion as; "the network of lexical grammatical, and other relations which provides links between various parts of a text" (180). In Hindi too "reference" is an important cohesive "device" (180). Actually, references are like sign posts, which guides the readers to go to other places in the text to allude to them. The pronouns are "most common reference items" in a vast number of languages, including English and Hindi (181). For example, in this sentence: "लज्जो घर में अकेली थी ,इसलिए उसे ही पानी लाना पड़ता था।" the word, "उसे" refers to "Lajjo" and is thus a reference device. Interestingly, the manner of introducing the "participants" and its references are almost similar in Hindi and English (Baker 1992: 181). However, this is not the case with Chinese or Japanese, where the nominal repetition is quite common. 
However, the grammatical conventions are quite different in the two languages. In certain instances, there may be no reference to the second person proper noun in Hindi, but when translated into English, it becomes imperative to add previously referred proper noun, ostensibly to make things clear. For example, in this original text: "नहीं-नहीं, मुझे तो बिलकुल भी नहीं लगी, पर जाऊंगा चाय पीकर ही।" कह कर प्रेम बाहर चला गया। उसने बता दिया कि साधारण जलन हुई और हिंग लगा लिया है । गाँव में इस प्रकार जल जाने पर हिंग का पानी ही लगाया जाता था।" (Kumar 2011: 31). Translation: "No... no, I have not been hurt, but today I will go only after having tea." said Prem and went back. He told Sumer that the injury was ordinary and she had applied hing (asafoetida). In villages, the people applied hing mixed with water in such cases of burns" (Sharma 38). So, it can be observed that in the second sentence, of the quoted text, the phrase "उसने बता दिया" has been translated as "He told Sumer" where the proper noun, "Sumer" was added to adhere to the cohesion rules of the target language. Though, the source text could stand, even in the absence of this proper noun, the repletion of this "pronominal reference" is imperative in the target language (Baker 1992: 183). The rules of cohesion in Hindi also allow such phrases as, "हिंग का पानी", because the source language readers can easily surmise the inherent meaning, as it is common practice in the rural societies in India, to mix hing with water for antiseptic use, but many target readers, especially non-South Asians may get grossly confused. This is because, in the first instance, they may not know, "what entity the hing is?" and even if they understand its meaning through glossary or otherwise, they are likely to wonder, "what the hing water is?". So, the translator had to add the word "mixed" to make things clear to such readers.

At some places the translator had consciously omitted certain lexical repetitions to make the translation smooth. This may also be termed as improvement of the text and may attract censor for the translator. He may also be accused of transgressing his limit, but at times the translator had to take on this alleged "misconduct" for the sake of good translation. Another reason to justify this delinquency is that the translator, not only has to be loyal to the author and the text, he also has to be faithful to the target audience. For example, in translation of these sentences: "घर से रास्ता सीधा नीचे उतरता था। बस प्रातः छ :बजे जाती थी। इसलिए वे प्रातः पांच बजे ही घर से चल पड़े।" (Kumar 2011: 43). Translation: "On the way from her house, there was a steep descent. The bus was to arrive at six in the morning. So, they had started at five" (Sharma: 58). Here, the word, "घर" in the second sentence was deleted, as this nominal reference was absolutely unnecessary, according to cohesion rules of the target language.

The translation of Lajjo was problematic for a different reason too. The Lajjo, is not a pure Hindi text, but a hybrid Kangri-Hindi text. On many instances, the Pahari dialect is peeping out from underneath the surface of this apparent Hindi text. So, instead of dealing with usual two languages in such inter-lingual transactions, the translator had to deal with three languages. In 
translation studies, un-transability is defined as, "a property of a text, or of any utterance, in one language, for which no equivalent text or utterance can be found in another language when translated" ("Untranslatability"). So, in Hindi or to be more precise, "Pahari-Hindi" has a number of words and terms which do not have equivalents in English. The novel Lajjo was also replete with many such words and terms. The expression such as, "धत तेरे की" (Kumar 2011: 34) and the contextualized "चल" has no English equivalent and the translator was forced to retain them as such and explain its meaning in the gloss. The Pahari connotational expression, "गोलपत्थर" is used at a number of places in the text, where ever the author wanted to say something about the village path and how people commuted on it. The Pahari word "dabotani" is a pigmy cricket bat like wooden structure to beat the soiled clothes. As it was impossible to explain the exact meaning of this word in a single English word, it was retained as such and its meaning was explained, in the text as was done by the source author.

The form, content dilemma is the biggest predicament for a translator, who erroneously strives to achieve equivalences at both levels. Unaware of extant translation theories and academic discourse in translation studies, the present translator too indulged in absolute fidelity, in the initial stages of translating this text. However, gradually it was realized that it is almost impossible to retain the sense as well as form at any given point of time. The translator has to sacrifice one or another at a given instance. Initially, the interlanguage transfer may appear to be extremely cordial, but later on the translation may end up as fragmented and fractured. Sooner or later, the translator bitterly realizes that one has to give up the impossible quest of integrating form and meaning. This is because of the fact, that the "syntactic structures" of a language is fixed and that while the translator does have optional "lexical choices", he has no such unrestricted "grammatical choices" (84). The difference in "grammatical devices" available to the translator in two languages, convolute the task of translator and there is every chance of missing the "conceptual information", that the translator wants to transfer in the target text (86). In addition, in some languages, certain "grammatical categories "may be optional, while in some they may be obligatory. For example, grammatical category of number is optional in languages like Chinese and Japanese, but not in English and Hindi. The linguistic propriety demands that the translator maintains the, "grammatical configuration" of the target language and should refrain from transgressing syntactic limits under any guise (84). Due to, "difference in grammatical structures" the translator has to do a lot of additions in translation and also effect innumerable deletions of lexical items from the source text (Baker 1992, 86). For example, in translation of this sentence: “यदि सब बड़े-बूढ़े आज्ञा दें तो मैं भी कहना चाहता हूँ।" एक नौजवान बीच में से उठ कर बोला । (Kumar: 2011: 22). Translation: "If the elders permit me, I would also like to put forth my views on the matter. A young man stood up amidst the discussion and said" (Sharma: 24). As can be 
observed the phrase, "on the matter" and the word "discussions" in reported speech was added to complete the sense. Moreover, in the collocation, "बड़ेबूढ़े" that makes perfectly acceptable sense in Hindi was simplified by the word "elder", because the translator was unable to find the equivalent collocation in the target language. Similarly, in the translation of this sentence: “दादा कमरे में बैठ गए थे ।" (Kumar 2011: 24), was translated as: "By now Grandfather had sat in a room, of the house" (Sharma: 27). Here the collocation "by now" and the word, "house" was added in the translation, to make it comprehensible. If this had not been done, the translation would have simply been reduced to incomprehensible equivalent. Just as the additions were done to keep the meaning intact, translator retorted to deletions for the similar reason. For example, in this sentence: "हर वर्ष, गर्मियों में इस गाँव को....।" (Kumar 2011: 26) was translated as: "Every summer, the village has to . .." (Sharma: 31). So here it can be noticed that, the word "year" was dropped, because the phrase "every summer" is sufficient to convey the intended meaning.

The rules for substitution and ellipses are also different in two languages. These important devices help the writer to achieves cohesion and a distinct texture in the text. Though it is really difficult for a translator to exactly reproduce such devices in the target text, the present translator attempted to achieve the same in translation of this sentence: "नहीं ...ऐसे नहीं...चाय पीकर।" (Kumar 2011: 20) that was translated as: "No... Not like this...but after taking tea" (Sharma: 21). Another instance where the translator tried to negotiate the translation of the sentence with marked ellipses, for a faithful yet creative translation. The original sentence: "लाजो की बात पूरी होने से पहले ही भगतराम बोल पड़ा , “नहीं-नहीं . . . तुम्हारा सब कोई है . . .जब से मैंने तुम्हे देखा है . . . सच, मैं . . .मैं . . . तुम्हारा ही हो गया हूँ ". . . दोनों आंखे निकाल, लाजो को घूरते हुए वह फिर बोला, “ठीक है न ... तुम भी . . . मेरी हो न. . . " (Kumar 2011: 48). Translation: 'Bhagat Ram intervened, even before Lajjo could complete, "No-No...all are yours...from the time, I have seen you...really, I...I...am all yours..." with his bulging out blood shot eyes, he stared at Lajjo and spoke again, "Is it Ok...you too... are mine" (Sharma: 67).

As the language itself is ambiguous, the dilemma becomes an integral part of any inter-lingual translation. To translate, a culturally distinct text, is not that easy and requires the translator to take a number of bold decisions for producing a meaningful and aesthetically rich translation. The translator cannot evade or side track, the problematic issues of the translation, which would be like, accepting the invincibility of untransbility. The translator is often at crossroads, in deciding about the choice of the right words, phrases and the sentences that will best serve his purpose. A translator facing the challenges of a difficult translation is like a man walking on a rope with deep valley below. 
Translation, Nation and Knowledge Society

\section{References}

BAKER, MONA. 1992. In other words: A Coursework on Translation. London: Routledge.

DHARANKAR, APEXA B. 2016. Translator's Creativity and Interpretive Community in Prose Translation. Shodhgnaga. Online: http://hdl.handle. net/10603/70207.

DWIVEDI, RAJIV RANJAN. 2012. Translation and the Question of Equivalence: To be or not to be?. In Sunil Sawant (ed.), Translation Studies: Theories and Application. 55-64. New Delhi: Atlantic.

Kumar, SHANTA. 2011. Lajjo. New Delhi: Bhartiya Prakashan Sansthan.

SHANKER, LAXMI and ANUBHA SHARMA. 2012. Impediments to literary Translation. In Sunil Sawant (ed.), Translation Studies: Theories and Application. 55-64. New Delhi: Atlantic.

SHARMA, SUMAN. (trans.) 2018. Lajjo by Shanta Kumar. Unpublished. 